Revista de la red interuniversitaria de estudios sobre las literaturas rioplatenses contemporáneas en Francia

16 | 2017

Esnobismos

\title{
Ese jardín vedado al medio pelo. Capítulos del esnobismo en Victoria Ocampo, Adolfo Bioy Casares y Jorge Luis Borges
}

\section{Mariano García}

\section{OpenEdition}

\section{Journals}

Electronic version

URL: http://journals.openedition.org/lirico/3590

DOI: $10.4000 /$ lirico.3590

ISSN: 2262-8339

\section{Publisher}

Réseau interuniversitaire d'étude des littératures contemporaines du Río de la Plata

\section{Electronic reference}

Mariano García, «Ese jardín vedado al medio pelo. Capítulos del esnobismo en Victoria Ocampo, Adolfo Bioy Casares y Jorge Luis Borges », Cuadernos LIRICO [En línea], 16 | 2017, Puesto en línea el 23 septiembre 2017, consultado el 08 mayo 2019. URL : http://journals.openedition.org/lirico/3590 ; DOI : 10.4000/lirico.3590

This text was automatically generated on 8 May 2019.

\section{$\Theta \Theta \Theta \Theta$}

Cuadernos LIRICO está distribuido bajo una Licencia Creative Commons Atribución-NoComercialSinDerivar 4.0 Internacional. 


\title{
Ese jardín vedado al medio pelo. Capítulos del esnobismo en Victoria Ocampo, Adolfo Bioy Casares y Jorge Luis Borges
}

\author{
Mariano García
}

1 Una consabida estrategia de la literatura sobre esnobismo es la de declararse esnob de antemano al momento de encarar cualquier asunto que tenga a los esnobs por protagonistas. Así, el gran clásico de esta literatura, The Book of Snobs de William Thackeray, lleva por subtítulo "by one of themselves"; el otro gran clásico al respecto, la Recherche proustiana, es un vertiginoso carrusel donde los esnobs se vigilan unos a otros a fin de descubrir, y eventualmente denunciar, quién es el más abyecto de todos, a lo que no escapa su narrador protagonista Marcel, en este terreno al menos alter ego transparente de Proust, que no vacila en presentarlo con toda la paleta de posibilidades del esnob social. Con su empaque acostumbrado, Virginia Woolf no teme preguntarse, en el título de una conferencia suya, si no es ella una esnob ${ }^{1}$, del mismo modo en que no vaciló en tratar como una esnob a Victoria Ocampo cuando esta fue a visitarla a su casa. De todo lo cual parece deducirse que "no hay peor esnob que el que no sabe que lo es". Asumir sin tabúes el esnobismo propio, desdramatizado, nos coloca en una posición de legitimidad a la hora de criticar a otros esnobs, que por definición serán siempre peores que nosotros, aunque solo sea por el hecho de no haberlo reconocido a tiempo. En ese sentido, como actitud psicológica se relaciona con el tópico de la modestia retórica, solo que la autoconciencia esnob necesita ser humorística, descontracturada, irónica y con la adecuada dosis de cinismo. Un esnobismo ciego, no reflexivo, resulta trágico y ahoga todo conato de ironía, aun en una pluma tan irónica como la de Flaubert.

2 La indignación que excita en nosotros el esnob está en relación con nuestro propio esnobismo : es preciso que uno mismo sea esnob para sufrir por causa del esnobismo de los otros. Solo el esnob conoce realmente al esnob porque imita su deseo, es decir la misma esencia de su ser. La distinción entre copia y original se borra : el mediador del 
esnob es también un esnob, una primera copia (Girard 70-71). Lacan lo resume en breve catecismo: "Qu'est-ce qui est desiré ? C'est le désirant dans l'autre" (Lacan en Brooks 108).

Emma Bovary es, quizá, uno de los primeros modelos trágicos del esnob, llevado a la categoría de caso clínico por Jules de Gaultier en su difundido estudio de 1902, Le Bovarysme, essai sur le pouvoir d'imaginer. Le siguen algunos títulos como "Der Snob" (1908) de Carl Einstein y "Der Snobismus als geistige Weltmacht" (1928), severo artículo de Franz Werfel que en cierto modo sintetiza la obsesión del mundo germano por este tema tan francés que ya suscitara comentarios en Schopenhauer, Nietzsche y Benjamin, y que podemos decir culmina con otras dos obras : el libro de René Girard Mensonge romantique et verité romanesque (1961), que ignora alegremente todo lo dicho en alemán al respecto y se concentra en tres focos problemáticos : Stendhal, Proust y Dostoievski ; y sobre todo el exhaustivo estudio sociológico de Pierre Bourdieu La Distinction. Critique sociale du jugement (1979).

4 En la Argentina, como en cualquier país americano, la posibilidad de un esnobismo parece ser a grandes rasgos eminentemente cultural, ya que América no conoce de primera mano ese objeto del esnobismo social que es la aristocracia. Sin embargo, la literatura nos demuestra que se puede también tener un esnobismo social : por imitación del francés, como casi todo lo que imitó la Argentina por tanto tiempo, dice Victoria (1926 : 131) : "Un argentino es, en suma, un ser capaz de experimentar ante una obra francesa por excelencia esa calidad de fervor y admiración que solamente se explica por el parentesco espiritual"; o por transformación : negar los antepasados europeos para darle categoría social al linaje criollo, como se puede apreciar en la siguiente cita de Borges : "En casa, que fueron muy snobs en materia de apellidos, hablaban, por ejemplo, del coronel Suárez, pero ahí acababa la familia. No iba más allá de la Independencia. Como la patria. Para nadie era un orgullo provenir de gallegos", (Bioy Casares 1058).

5 En general, el argentino se cuida mucho de quedar como un tilingo. Es necesario que se muestre enterado, moderno, que no se limite a cultivar el gusto por las expresiones locales, en suma, algo parecido a lo que Borges formuló en "El escritor argentino y la tradición". De hecho, Borges y Victoria Ocampo son por años los árbitros de la elegancia literaria argentina, tanto en calidad de arbiter novarum rerum como en calidad de sancionadores y guardianes de la tradición. No hace falta tener una imaginación desbocada para trazar paralelos entre el mundo de Guermantes y la côterie de Sur, si consideramos, por otra parte, cierta similitud entre la sociedad de la Tercera República que retrata Proust y que Adorno define como "sociedad de apropiación" y la sociedad argentina de la época : espacios vacantes de poder que están al alcance de los nuevos ricos mientras que la riqueza acreditada intenta elevar defensas culturales para evitar la invasión. "Son, ambas, sociedades de prestigios exagerados o falsificados, de arribistas y de esnobs" (Matamoro 1986 : 168).

6 El mencionado episodio de la desencantada visita de Victoria a Virginia Woolf, o el muy citado capítulo de Witold Gombrowicz cenando en casa de Bioy Casares y Silvina Ocampo, ilustran dos momentos característicos de la condición transitiva del esnobismo : la inglesa esnob que pone los ojos en blanco ante la sublime Vita Sackville humilla a su apasionada admiradora sudamericana; el conde Gombrowicz, que es en realidad un falso conde, se burla pesadamente de las solemnidades de Borges y de Mallea y en general de todo lo relativo al círculo de Victoria Ocampo ${ }^{2}$. Por su parte, Borges y Bioy hablan del "conde pederasta y escritorzuelo Gombrowicz" (Bioy 181). ¿Por qué Gombrowicz, con su vitriólica 
iconoclastia para con lo europeo, y que encuentra tan maravillosa la virginidad cultural de la joven Argentina, finge ser aristócrata en un país donde la aristocracia no existe? ¿Borges y Bioy lo convierten en el blanco de sus burlas porque adivinan un insidioso esnobismo ? Tal vez sea necesario reproducir completa la entrada del domingo 22 de julio de 1956 :

BORGES : "En una reunión, el conde pederasta y escritorzuelo Gombrowicz declara : "Yo voy a decir un poema. Si en cinco minutos nadie propone otro tendrán que reconocer que soy el más gran poeta de Buenos Aires". Recita :

Chip Chip llamo a la chiva

(Scherzo, no desprovisto de ironía, porque chip chip se usa para llamar a las gallinas.)

Mientras copiaba yo al viejo rico

(Parte descriptiva. No significa "remedaba yo al viejo rico" sino "copiaba a máquina lo que el viejo rico dictaba".)

Oh rey de Inglaterra jviva!

(Castañeteos. Exaltación patriótica.)

El nombre de tu esposo es Federico.

(Dénouement aristotélico.)

"Córdova Iturburu trató de leer algo, pero no encontró las papeletas. Gombrowicz se declaró rey de los poetas. [...]

BORGES : "Sabato dice que el escritor debe abandonar su torre de marfil y acercarse al pueblo. Anderson Imbert le respondió : "Usted habla como un aristócrata. Yo no tengo que ir al pueblo, porque soy del pueblo. Creo que el pueblo se ha portado muy mal aquí y que debe tener conciencia de su culpa".

BIOY : "I would hardly describe him as an aristocrat", observó Alicia Jurado sobre Sabato" (Bioy Casares 181-2).

7 Tenemos aquí diversas capas significativas : Gombrowicz recita un poema "moderno" con ánimo beligerante (y donde aparecen un viejo rico y un rey, objetos de un esnobismo sarcástico), declarándose entre burlona y pedantescamente el mejor y cumpliendo de manera cabal con la definición que ve en el esnob a quien busca distinguirse de otros sin beneficiarse de un reconocimiento confirmado por una tradición (Bell y Kuhnle 2). Los comentarios irónicos de Borges intercalados en la recitación del poema desenmascaran al esnob : pese a su intención absurda, el poema es interpretable y por consiguiente ni tan moderno ni tan radical como pretende el escritorzuelo. En una reduplicación sorprendente, especie de variación asociativa, el diálogo entre Sabato y Anderson Imbert vuelve a dramatizar la situación del esnob y su desenmascaramiento, con la coda perfecta de Alicia Jurado (otro jurado del buen gusto y de la sangre noble) en inglés, remota heredera del chic anglais que en la Recherche representa Mme de Farcy. En tanto que Gombrowicz asume el esnobismo de la provocación y de una presunta contracultura (parece haber ignorado que a Borges le fastidiaba tanto como a él la legitimación cultural sancionada por lo francés), para Borges y Bioy la distinción que busca el esnob en su intento por anticiparse a la moda es una puerilidad en la que ellos no pueden caer. En cuanto al factor común a todo esnobismo, la vanidad y el deseo de superar a los otros (Bell y Kuhnle 2), parece estar aquí repartido equitativamente.

8 Una genealogía del esnobismo en la Argentina no puede dejar de lado algunos aspectos que se acercan bastante a dicho concepto y que eclosionan en el paso del siglo XIX al xx. Hay al menos dos momentos reveladores: la denuncia del guarango y otras tipologías asociadas que presenta José María Ramos Mejía en Las multitudes argentinas (1899), figura ficcionalizada una década atrás por Eugenio Cambaceres en la xenófoba En la sangre (1887), por un lado. En los dos últimos capítulos de Las multitudes argentinas habla Ramos 
Mejía de "La multitud de los tiempos modernos", donde el guarango, junto con el burgués aureus, el canalla y el huaso son "productos de la evolución" del inmigrante. "En la paleontología social, el guarango [...] es un invertido del arte, y se parece a los invertidos del instinto sexual que revelan su potencia dudosa por una manifestación atrabiliario de los apetitos. Necesita de ese color vivísimo, de esa música chillona [...] quiere las combinaciones bizarras y sin gusto de las cosas [...] para satisfacer especiales idiosincrasias de su sensibilidad" (165-6). En suma, el gusto del guarango es un gusto pervertido.

9 Por otro lado, resulta llamativa la obsesión con la simulación y el simulador, que cristaliza en Los simuladores de talento en las luchas por la personalidad y la vida (1904) también de Ramos Mejía, y en Psicología de los simuladores (1903), de su discípulo José Ingenieros. El guarango es un advenedizo peligroso cuya misión en la vida es escalar socialmente hasta instalarse en un lugar que no le corresponde. El simulador, un impostor que finge saber lo que no sabe, o poseer cualidades que no posee; como en el caso del esnob, el simulador obra por sugestión e imitación, no hay deseo espontáneo sino deseo copiado (Girard 13), pese a que sea fundamental la afectación de espontaneidad y originalidad (ibid. 73). Ambas figuras son solidarias o pueden considerarse dos caras de una moneda, tal como en efecto ocurre con el personaje de la novela de Cambaceres, donde ambos aspectos confluyen. En medio de la xenofobia imperante en el cambio de siglo, las metáforas reaccionarias del discurso positivista sirven para "demostrar" que estos astutos personajes llevan su inautenticidad oculta bajo la piel, más precisamente en la sangre, pero que tarde o temprano los traiciona algún gesto delator ${ }^{3}$. La diferencia entre el mero arribista y el esnob radicaría, según los parámetros de Benjamin, en el matiz estetizante de este último (Benjamin 209-210): el arribista tendrá gustos primitivos que a la larga no podrá disimular, en tanto que el esnob ha cultivado su gusto.

Si con el Modernismo se rompe la hegemonía de la clase alta sobre la producción literaria, ruptura encabezada por Paul Groussac y continuada por "hidalgos pobres" como Darío, Lugones, Larreta (Matamoro 1975, 16) y algo más tarde Mallea, el cultivo del buen gusto literario y del buen gusto general sigue siendo prerrogativa de lo que Mujica Láinez llama en su novela El gran teatro los happy few. El gran teatro (1979) narra desde la perspectiva de un adolescente provinciano una supuesta función de gran abono de Parsifal de Wagner en el teatro Colón. Calcada de la larga escena en la opéra que vive Lucien de Rubempré en Illusions perdues de Balzac, sirve a Mujica Láinez como dispositivo de exotismo de la clase alta, sus parásitos, etc. El código que a lo largo del texto permite detectar a la buena sociedad de la chusma es el decir "voy a Colón" (uso correcto) en lugar de "voy al Colón" (uso abominable) ; y a la inversa, hay que decir "voy al Tigre" y no "voy a Tigre". ${ }^{4}$ Una imitación de las costumbres de la aristocracia europea, que con el ascenso de la burguesía se vio obligada a asimilar sociolectos a la par que a crear reglas comunicativas secretas y cambiantes para que los extraños no pudiesen aprenderlas (Matamoro $1975: 264$ ).

En la generación de Victoria, no por casualidad, aparecen varias mujeres de la buena sociedad porteña que encabezan organizaciones de estímulo cultural. Bebé Sansinena, las hermanas Del Carril, Adelia Acevedo, Tota Atucha, Magdalena Bengolea. Pagan a los maestros, dirigen el gusto, a veces lo tiranizan. Son las que Manucho Mujica designaba, irónicamente, como les précieuses de Buenos-Ayres, incluyendo entre ellas a un précieux, Arturo Jacinto Álvarez (Matamoro 1986, 19).

11 Precisamente uno de los antecedentes que se suele invocar para el esnobismo son los salones de esas mujeres sabias que retrata primero Molière y que más tarde terminarían produciendo tanto horror a Rousseau en una época en la que se plantea una tensión que 
pone al artificio entre el cuestionamiento y la legitimación. "El valor estético ligado a las 'maneras agradables' se imputa a la persona, a su 'mérito personal' : se advierte enseguida un componente narcisista muy fuerte, en la medida en que el proceso distingue entre individuo y destino en una sociedad escogida" (Starobinski 72). Los círculos del preciosismo ayudan a conformar así un "narcisismo de grupo" en el que no casualmente los hombres se feminizan en el atuendo y en el que surge el género literario del retrato y particularmente del autorretrato (ibid.). Es también la época de la lisonja, el halago más o menos interesado que modifica la dinámica meramente verbal hacia un paradigma podríamos decir pragmático: palabras contra favores, en un juego de vanidades tempranamente denunciado por La Rochefoucauld.

Hay sin embargo dos puntos que alejan a Victoria Ocampo del mundo que describe Proust. En la belle époque que retrata el autor de Jean Santeuil la nobleza, caído el Segundo Imperio, queda apartada de la clase dirigente, lo que no es el caso en la Argentina. En segundo lugar, el propio Proust es responsable de cierta autoconciencia de salonera en Victoria : hay que evitar por todos los medios caer en las actitudes grotescas de la Verdurin y sus enemigas. Por lo tanto Victoria fundará un salón "progresista" donde se elogian las novedades y del que quedan excluidas las mujeres (Matamoro 1986, 170).

Las diferencias e incluso el choque entre el orbe francés y el argentino en este respecto aspiran a ser ilustradas en un cuento no especialmente brillante de los Nuevos cuentos de Bustos Domecq (1977), ubicado entre el primero de la colección y la famosa "Fiesta del monstruo", titulado "Más allá del bien y del mal". Al parecer se trataba de una vieja idea de Bioy, que ya menciona en su diario en 1969, y que para 1971 discutía con Borges con la intención de trabajarla a dúo. Es la historia de un argentino "muy snob" (Bioy Casares 1369), cónsul en el balneario de Aix-les-Bains, donde en su soledad se ve atraído por una familia francesa sobre la que se pregunta si será "gente bien", pues es fácil equivocarse con extranjeros. En poco tiempo hechizado por el aura decididamente "bien" de la familia, que no obstante aprovecha cualquier ocasión para endosar al cónsul abultadas cuentas de comidas y tragos que han compartido, comprueba que el viejo barón, un afable anciano, pretende envenenar a una de sus nietas, con la que el cónsul acomete un flirteo incierto. Al enterarla de los planes de su abuelo, la muchacha le revela risueña que el anciano es un asesino fracasado de cuyos intentos la familia está al tanto. Revelación fulminante para el cónsul, que considera extasiado que sólo los aristócratas, que están como el superhombre nietzscheano más allá del bien y del mal, son capaces de algo así. Tras la última cena con ellos, el cónsul empieza a sentir síntomas de envenenamiento.

El cuento tiene una impronta muy definida del estilo de Bioy Casares, al fin y al cabo el impulsor de una idea que no sabemos si terminó de interesar a Borges. Sí queda registrada la vacilación en cuanto al tono (Bioy Casares 1372) : no están seguros acerca de cómo contarlo, si debe ser una experiencia del propio Bustos Domecq, si hay que incluir a "Macedonio" pero sobre todo, si el cuento debe ser serio o cómico. Es sugestiva la vacilación ya que el estatuto trágico, cómico o aun grotesco del esnobismo es poco claro y no garantiza un efecto determinado. En cuanto a Macedonio, por esta época Borges venía de escribir "El congreso", cuento donde se da una serie de detalles que remiten a Macedonio Fernández : ya en la segunda línea se habla de "la gran sombra del macedonio (sic)"; el amigo poeta del narrador tiene por primer apellido "Fernández" y también se menciona más adelante a un "del Mazo" (apellido de la madre de Macedonio Fernández). La idea misma de un "congreso del Mundo", con su presidente de trunca carrera política, es un inequívoco guiño a la figura de Macedonio Fernández y a la poética alegórica de su 
Museo de la Novela de la Eterna. En la entrada del 26 de junio de 1971 Borges da a entender que el Fernández Irala de su cuento "El Congreso" es "alguien como Macedonio" (Bioy Casares 1372). Sin embargo, la idea que propone Borges es la de dejarse matar por admiración, no por esnobismo, acaso una manera demasiado poco noble de morir según su criterio. Con esto quizá se refuerza la hipótesis de la escasa participación de Borges en el cuento "Más allá del bien y del mal" y su acotado interés por el esnobismo como tema literario. Por otra parte es lógico pensar que la invocación de Macedonio serviría para favorecer el tono humorístico, aunque no se pueda decir que la presencia de este último en "El congreso", aun disfrazada y aludida, redunde en alguna clase de efecto cómico. Asimismo, la figura de Macedonio parece reacia a las formas más evidentes de esnobismo : no se entrega a la vanidad habitual del escritor (piénsese en la manera negativa y poco solemne de presentarse en Papeles de Recienvenido) ni parece interesado en imitar ninguna moda literaria: su deseo tiende un puente entre la vida y la muerte y no necesita de ningún intermediario.

El resultado por el que se decantaron Bioy y Borges es una variante del costumbrismo plebeyo que practica con fruición Bioy Casares, muchos de cuyos chistes y frases parecen salidos de su Diccionario del argentino exquisito. ${ }^{5}$ Sin embargo, ya fue señalado en la obra en colaboración de ambos escritores la convivencia de diversos códigos, como la vestimenta o la alimentación, que establecen oposiciones inmanentes entre lo vulgar o no vulgar, lo correcto y lo incorrecto, lo legítimo y lo ilegítimo (Avellaneda 67), lo cual hace pensar en "Más allá del bien y del mal" como epítome de las censuras de clase en que incurre la "hilarante" obra a dúo (García 319-320). El recurso epistolar permite desplegar los rasgos de clase social de Félix Ubalde, apodado "el Indio" : sus expresiones poco elegantes ("Sin un compatriota con quien relincharme, no hay modo de pasar el tiempo", 382), su pasada vida social ("Un abrazo a toda la barra de la Confitería del Molino", 382); como auténtico esnob que es, vive pendiente del esnobismo de los demás (“[...] la plana mayor del comedor se doblaba en serviles reverencias ante el arribo de los Lagrange”, 383 ; “Poyarré [el asistente de Ubalde], con el servilismo que le es propio, consiguió que aceptáramos una vuelta de anís", 385). Aunque Ubalde manda a su asistente averiguar los antecedentes de la familia Grandvilliers-Lagrange, inicialmente se manifiesta muy preocupado acerca de la auténtica condición de esta gente.

Lo que me trabaja es la duda de si realmente son gente bien. Entendeme : no tengo nada contra el medio pelo, pero tampoco olvido que soy cónsul y que debo guardar, aunque más no sea, las apariencias. Un paso en falso y ya no levanto cabeza. En Buenos Aires no corrés ningún riesgo : el sujeto distinguido se huele a la media cuadra. Aquí, en el extranjero, uno se marea : no sabés cómo habla el guarango y cómo la persona bien (Bioy-Borges, 384).

16 Resulta fundamental no equivocarse en la elección del objeto de adoración : un error al respecto devolvería al esnob a la chusma, al medio pelo del que desea destacarse y al que fatalmente pertenece si nos atenemos a la descripción que ofrece Estela Canto de la famosa confitería del Molino :

... una típica confitería de clase media, que exhibía en sus vitrinas tortas de boda o de cumpleaños y alquilaba sus salones para fiestas de medio pelo. También concurrían allí algunos diputados y senadores, en la Argentina esta gente no suele ser elegante. Era, sobre todo, un lugar al que señoras ociosas acudían por la tarde para tomar té y engullir masitas, señoras rotundas o francamente obesas, vestidas con una ostentación poco acertada (Canto 1989 : 186).

17 Sin embargo, una vez aclarado el angustiante punto sobre la autenticidad de la nobleza de la familia que lo obsesiona, el así llamado Indio vivirá su cercanía al “alto nivel” como una 
serie de revelaciones cuasi místicas. El deslumbramiento esnob funciona aquí a un punto tal que donde hay mezquindad, avaricia, aprovechamiento y perversidad, el cónsul ve elegancia, generosidad, superación de la obtusa moral burguesa. "Para el observador argentino, el roce con la aristocracia más rancia, provoca verdadero interés" (385); "Comprendí en un instante que me hallaba ante un ser de otra especie, de esos que planean muy alto" (385); “[...] cuando el barón en persona me pasó, en propia mano, la vinagrera, que resultó vacía, yo hubiera contratado un fotógrafo, para remitir la instantánea a la Confitería del Molino", 387) ; “Mi temporada aquí me está resultando un verdadero viaje de estudio. Sin mayor esfuerzo me aboco a un examen a fondo de esa napa social que, dicho sea de paso, está a punto de agotamiento" (388) ; y la epifanía final : "Ante mi visión de argentino se abrió de golpe esa gran terra incognita, ese jardín vedado al medio pelo : LA ARISTOCRACIA EXENTA DE PREJUICIOS" (390).

En este caso la moraleja que formulamos al comienzo de este trabajo aparece diáfana : "no hay peor esnob que el que no sabe que lo es", lo cual tiene consecuencias trágicas para Félix Ubalde, que en su perfecta combinación de adulación y curiosidad (aleación que define para Benjamin todo esnobismo, 208), paga la tilinguería con la vida ; y cómicas para el lector según la intención irónica del texto. Caso de esnobismo social, el choque resulta tanto más fuerte cuanto que el protagonista proviene de una sociedad sin aristocracia y es sacudido -y arrasado- por el aura de prestigio con que imbuye, más por autosugestión que por evidencias de la realidad, a esta familia que no duda en sacar partido de un ingenuo advenedizo. Ubalde presenta de forma sintética los síntomas que Franz Werfel observaba en esa especie de neurosis que creía encontrar en el esnobismo : una necesidad de hacerse valer que se ha vuelto patológica ("der krank gewordene Trieb zu Geltung") y que conlleva los siguientes puntos: culto de la novedad, elección de cosas exquisitas, excentricidad, perversidad, culto del crimen (Kuhnle 4).

19 Algunos textos aislados en la literatura argentina vuelven sobre el tema, no como tópico exclusivo sino como subtema, atmósfera o telón de fondo, tal el caso de Sara Gallardo ( Pantalones azules; Los galgos los galgos), Manuel Puig (La tajada, Pubis angelical) o Juan José Hernández (La ciudad de los sueños), además del ya citado Mujica Láinez, verboso aunque peligrosamente vacuo avatar proustiano al que le sobraba estirpe y le faltaba la lucidez implacable del "resentido social". Recordemos que Victoria, al comparar a Proust con Vita Sackville-West, le reprochaba a este haber descrito el mundo de la nobleza desde fuera y no desde dentro y que como outsider que era estaba invalidado para ejercer subjetivamente tal crítica (Ocampo $1963: 126)$, si bien la propia Victoria tiende a ofrecer anécdotas banales de hombres de la cultura o del poder.

20 Al mismo tiempo sorprende que escritores ligados a Sur y a Victoria Ocampo como su hermana Silvina y José Bianco eviten la utilización de la geometría del esnobismo, aun cuando sus ficciones no sean ajenas a esquemas de triangulación del deseo, de acuerdo al esquema ya comentado de mediación propuesto por Girard (70-71). Una posible respuesta tal vez se encuentre en el hecho de que, más allá de su mayor o menor humor, toda denuncia de esnobismo, incluso pese a la figura atenuante de reconocerse esnob para ejercer libremente la crítica a otros esnobs, implica un sentimiento de superioridad que no todos los escritores, o bien no todas las poéticas comparten.

21 Tanto la psicoanalista Helene Deutsch como el filósofo Hans Vaihinger estudiaron desde sus respectivos campos el problema del "como si" (als ob). Para Vaihinger la conciencia es doble y el hombre nunca puede captar su verdadera identidad; hace que lo real surja de lo irreal. Deutsch por su parte se interesó en personalidades que difícilmente se 
conformaban con una sola identidad, concluyendo que la impostura permitía vivir una vida acorde a las fantasías personales sin atribuir esa vida al yo, ya que la "verdadera" identidad nunca está a la altura de las fantasías. Nuestra fascinación, así como nuestra ansiedad frente a la impostura, a la que podemos asimilar aquí con el esnobismo, tiene que ver con la inadecuación entre realidad e imaginación y expresa el deseo de reescribir nuestro yo, una tentación que en la mayoría no pasa del fantaseo (Brooks 72-3) pero que en el esnob puede asumir rasgos compulsivos que lo convierten en un "tipo" muy atractivo para la plasmación ficcional, precisamente porque se convierte en una figura de la relación inestable entre realidad y ficción.

\section{BIBLIOGRAPHY}

Avellaneda, Andrés. El habla de la ideología. Buenos Aires : Sudamericana, 1983.

Bastos, María Luisa. "Sur y los Testimonios de Victoria Ocampo". Madrid : Revista Iberoamericana 110-111, 1980.

Bel, Jacqueline y Till R. Kuhnle. “Préface”, Germanica no 49 "Péripéties du snobisme”, 2011. Recurso electrónico : http://germanica.revues.org/1363

Benjamin, Walter. "The Image of Prout”, Illuminations. Essays and Reflections. Edited and with an introduction by Hannah Arendt. New York : Harcourt Brace, 1968, pp. 201-215.

Bioy Casares, Adolfo. Borges. Edición al cuidado de Daniel Martino. Buenos Aires : Destino, 2006. Borges, Jorge Luis y Adolfo Bioy Casares (1977). "Más allá del bien y del mal”, Nuevos cuentos de Bustos Domecq, en Jorge Luis Borges, Obras completas en colaboración. Buenos Aires : Emecé, 1979, pp. 381-391.

Borges, Jorge Luis. "El congreso", El libro de arena en (1989) Obras completas II. Buenos Aires: Emecé, 1975.

Brooks, Peter. Enigmas of Identity. Princeton and Oxford: Princeton University Press, 2011.

Canto, Estela. Borges a contraluz. Madrid : Espasa Calpe, 1989.

García, Mariano. "Bioy Casares y la autofiguración póstuma”, en Debates actuales del hispanismo. Balances y desafíos críticos. Santa Fe : Universidad Nacional del Litoral, 2016, pp. 316-325.

Girard, René (1961). Mentira romántica y verdad novelesca. Barcelona : Anagrama, 1985.

Gombrowicz, Witold. Diario argentino. Buenos Aires : Adriana Hidalgo, 2001.

(1952). Trans-Atlantique. Paris : Gallimard, 1976.

Kuhnle, Till R. "Bovarysme et snobisme, deux symptômes de la nervosité des nations. Étude de cas : Der Mann ohne Eigenschaften", Germanica no 49 "Péripéties du snobisme", 2011. Recurso electrónico : http://germanica.revues.org/1370; DOI : 10.4000/germanica.1370

Matamoro, Blas. Oligarquía y literatura. Buenos Aires : Ediciones del Sol, 1975.

Matamoro, Blas. Genio y figura de Victoria Ocampo. Buenos Aires : Eudeba, 1986. 
Mujica Láinez, Manuel. El gran teatro. Buenos Aires : Sudamericana, 1979.

Reffet, Michel. "Franz Werfel. Le snobisme, père de tous les maux", Germanica no 49 "Péripéties du snobisme”, 2011. Recurso electrónico : http://germanica.revues.org/1371; DOI : 10.4000/ germanica. 1371

Starobinksi, Jean (1989). Remedio en el mal. Crítica y legitimación del artificio en la era de las luces. Madrid : Antonio Machado, 2000.

\section{NOTES}

1. “Am I a snob?", conferencia pronunciada en 1936 en el Memoir Club y recogida en Moments of Being, Harvest Books, 1985. Como dato curioso, cabe consignar que por su primer matrimonio Leslie Stephen, padre de Virginia, era yerno de Thackeray. Victoria Ocampo le dedica Virginia Woolf en su diario, Sur, 1954, y menciona su visita en Testimonios VIII serie, Sur, 1971.

2. V. el capítulo 4 de Trans-atlántico de W. Gombrowicz.

3. Cf. Oscar Terán, Vida intelectual en el Buenos Aires fin-de-siglo (1880-1910). Derivas de la "cultura científica". Buenos Aires: FCE, 2000 y Jorge Salessi, Médicos, maleantes y maricas. Higiene, criminología y homosexualidad en la construcción de la nación Argentina (1871-1914). Rosario: Beatriz Viterbo; 1995.

4. V. Norma Carricaburo (dic-en 1994). "Los clasificadores léxicos y la clase alta argentina", en Letras. $n^{\circ}$ 29-30, Buenos Aires.

5. Publicado en 1971 como Breve diccionario del argentino exquisito (Buenos Aires: Barros Marino) con el seudónimo de Javier Miranda.

\section{ABSTRACTS}

Any approach to Argentinian snobbism would be unthinkable without considering a chapter on the group of writers and intellectuals gathered around the literary journal Sur. If snobbism features the imitation of the desire of the other, it seems at the same time fundamental to assume one's own snobbism in order to be in a plausible moral position to criticize it in others. We will survey here different manifestations of this, concluding with the analysis of a short story where Borges and Bioy Casares treat with sarcastic humor a phenomenon not alien to their own world.

Un acercamiento al esnobismo argentino resulta difícil de pensar sin dedicarle su capítulo al grupo reunido en torno a la revista Sur. Si el esnobismo se caracteriza como la imitación del deseo del otro, al mismo tiempo parece esencial asumir el esnobismo propio para poder criticarlo en otros. En este trabajo repasamos distintas manifestaciones al respecto, para concluir con un cuento donde Borges y Bioy Casares se acercan con humor corrosivo a un fenómeno que no les era ajeno.

Une approche au snobisme argentin reste difficile à penser sans dédier son chapitre au groupe rassemblé autour de la revue Sur. Si le snobisme se caractérise par l'imitation du désir de l'autre, de même il semble essentiel d'assumer le propre snobisme afin de le critiquer chez les autres. 
Avec cet article nous proposons de réviser différentes manifestations à cet égard, pour conclure avec un récit où Borges et Bioy Casares abordent avec humour corrosif un phénomène qui n'était pas étranger à leur monde.

INDEX

Palabras claves: J. L. Borges, A. Bioy Casares, Victoria Ocampo, esnobismo

Keywords: J. L. Borges, A. Bioy Casares, Victoria Ocampo, snobbism

Mots-clés: J. L. Borges, A. Bioy Casares, Victoria Ocampo, snobisme

\section{AUTHOR}

MARIANO GARCÍA

Centro de Estudios Comparados María Teresa Maiorana (UCA) - Conicet

Compilador junto con Mariana Dimópulos del libro Escritos sobre la mesa. Literatura y comida, Buenos Aires, Adriana Hidalgo, 2014 